\title{
How is it Done? Comparison between the Margin Calculation Metbodology of Central Counterparties and Clearingbouses
}

\author{
Melinda Friesz \\ Corvinus University of Budapest \\ melinda.szodorai@gmail.com \\ Kata Váradi \\ Corvinus University of Budapest \\ kata.varadi@uni-corvinus.hu
}

\begin{abstract}
SuMmary
Clearinghouses and central counterparties have become the backbone of financial markets by stepping between trades, facilitating securities trading, and derivative transactions on exchanges and overthe-counter markets. In the literature and in practice, too, the notion of clearinghouse and central counterparty are used as synonyms, but there is still a slight difference that highlights their distinction. This paper focuses on the margin calculation methodology of these institutions and emphasizes the contrast between the two. Results show that although capturing the same risks, clearinghouses' margin requirement is better from a procyclicality and cash flow management point of view; however, central counterparties margining is more prudent based on our results.
\end{abstract}

KEYWORDS: initial margin, maintenance margin, variation margin, central counterparty, clearinghouse

JEL CODES: G15, G17, G18

DOI: https://doi.org/10.35551/PFQ_2021_3_5 
Since the global financial crisis (GFC) of 2007-2009, central clearing has come a long way. Clearinghouses' and central counterparties' (CCPs) role in the economy has improved, expanding as well. Their main role in the market is to clear and settle trades. The financial crisis emphasized the vulnerabilities of the financial system, so the aim was to shape the market so the overthe-counter (OTC) derivatives markets trades outside the exchanges - and the risks associated with them should be handled, resulting in more transparency, so these trades were aimed to be cleared through these market infrastructures. The efficiency of the central clearing was proven by the windingdown process of the Lehman Brothers, demonstrating that OTC transactions carried a considerable counterparty risk. Steps were taken to avoid the repetition of such intense stress, and regulators realized the importance of decreasing counterparty risk during trading. Counterparty risk can be managed through clearing bilaterally or centrally (Gregory, 2014). During bilateral clearing, two trading partners enter into a master agreement with each other. This agreement has an annex, called the credit support annex (CSA), that requires both parties to provide collateral (Hull, 2018). Compared to this, if a CCP steps between them, then every trading partner is trading with the CCP, as shown on the right-hand side of Figure 1. The left-hand side shows the absence of a CCP, representing the bilateral clearing case.

During the summit in Pittsburgh on $26^{\text {th }}$ September 2009, the participating G20 leaders set a wide-ranging goal for the whole financial system, agreeing that all standardized OTC derivative contracts should be cleared through CCPs by the end of 2012. The other aim of the financial reform was to enhance transparency and make these contracts reported to trade repositories (EMIR (5),
2012). Moreover, higher capital requirements were set for the non-centrally cleared OTC derivatives (Gregory, 2014). The regulatory framework for CCPs was established based on this agreement, so in the USA, the DoddFrank Wall Street Reform and Consumer Protection Act (DFA) was enacted in July 2010, while in July 2012, the European Market Infrastructure Regulation (EMIR) in the European Union (EU).

The Committee on Payment and Settlement Systems and the International Organization of Securities Commissions (CPSS-IOSCO) issued the Principles of Financial Market Infrastructures (PFMI, 2012) in April 2012. The principles became the global benchmark for the regulatory requirement for CCPs (RTS (2), 2013). All standardized OTC trades between financial institutions must be cleared through a CCP. This regulation's exceptions are the non-financial institutions if their position does not exceed the clearing threshold (Doyle et al. 2016) in the framework of the EU regulation; while in the case of the US regulation, the non-financial firms are exempted if their transaction is entered in order to hedge commercial risk (Gregory, 2014). Finally, foreign exchange transactions are exceptions, too (Hull, 2018).

The regulatory requirement, both the DFA and the EMIR, requires CCPs to manage multilevel guarantee systems. Market participants must pay two significant guarantees within this guarantee system: the margin and the default fund contribution this latter element is called guaranty fund in the case of the clearinghouses. The paper's primary focus is the margin requirement calculation considering the requirements put by the regulator. The authors will analyze how clearinghouses and CCPs calculate the margin value on asset level and point out differences the similarities. The focus of this paper includes the explanation of the different 


\section{BILATERAL VERSUS CENTRAL CLEARING ON OTC MARKETS}

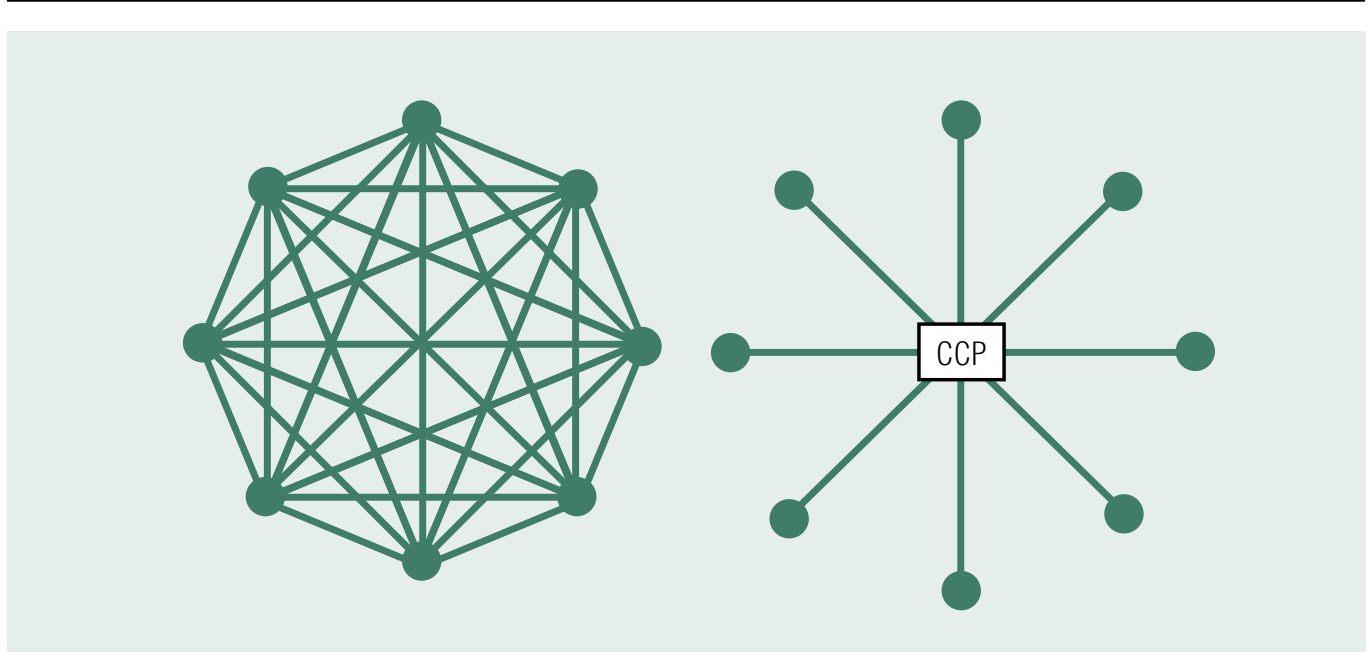

Source: Hull, 2018, pp. 57.

margin-related notions, like the variation margin, initial margin, maintenance margin, and the margin call.

\section{LITERATURE REVIEW}

Berndsen (2020) sums up the main academic findings on CCPs and classifies them into five main groups: the clearing itself, the optimal number of CCPs, the size of the default waterfall, the end of the default waterfall, and the default waterfall skin-in-the-game related researches. This paper focus on one element of the default waterfall, namely the basic notions of the margin calculation.

\section{Advantages and disadvantages of central clearing}

Central clearing and the presence of CCPs proved to be effective during and after the global financial crisis where Lehman Brothers defaulted on 15th September 2008. This was the biggest default in CCP history (Fleming and Sarkar, 2015; Bernstein et al., 2019), and the unwinding process was one of a kind. The ' $C M E$ closed out the cleared derivatives portfolio, which had a net value of around \$21 billion in May 2008, within a few days using Lehman's margin resources. The margin was sufficient to cover auction-related losses amounting to \$1.2 billion'. (King et al., 2020). LCH.Clearnet's SwapClear service provided nearly half of the world's interest rate swap positions at the default time. While the unwinding took several months to reach an end, the trades managed by the LCH Clearnet handled the default efficiently within hours by suspending insolvent Lehman entities and having around USD 2 billion as an initial margin account from Lehman time (Gregory, 2014, Norman, 2011). The LCH.Clearnet faced massive failures before, like the default of Barings in 1995, which was handled without any severe problems (Gregory, 2014). McPartland and Lewis (2017) point out further examples of 
clearing member defaults resulting in massive losses but not having Armageddon-like effects on the whole system. Every example shows the advantages of CCPs and proves that they are shock-resistant and can protect the system they clear. The last event that had a higher impact on the clearing activity was in September 2018 on the Swedish market, but the event also endorsed the CCP and its advantage. (King et al. 2020). Béres (2018) also higlights the benefits of CCPs and its overall positive effects on the economy.

There are several advantages and disadvantages of CCP clearing from a CCP's perspective compared to bilateral trading without a CCP. The essential advantage of central clearing, on the first hand, is transparency. Its offsetting benefits, loss mutualization through the default fund give heightened resistance for the market and its participants. On the other hand, legal and operational efficiency is also achieved while liquidity and default management are an overall advantage of the CCP's presence on the market (Gregory, 2014), and risk mitigation concerning counterparty risk is achieved (ICE, 2021). While the main disadvantages include moral hazard; adverse selection; bifurcation; procyclicality; assets are less effective for hedging if they have to be centrally cleared. The perspective of traders is vital to be noted as well because among the disadvantages CCPs have are that they are more costly than bilateral clearing without a CCP; only highly liquid assets can be used as collaterals. Some factors are ambiguous, whether they are advantages or disadvantages of central clearing (Turing, 2012).

The increased level of interoperability among CCPs intensifies systemic risk without enhancing the financial resources of each interoperating CCP. Duffe and Zhu (2011), Amini et al. (2016), Lopez and Saeidinezhad (2017), Health et al. (2016), Gullo (2020),
Tywoniuk (2020), and several others are primarily concerned with the potential for contagion due to their high level of interconnectedness. King et al. (2020) address the problem from a procyclicality point of view. Baker (2020), Huang and Takáts (2020) highlight the risks associated with the CCPs' own capital included in the system and the incentives it can shape, which may be harmful to the whole system, significantly if incentives of clearing members and the CCP is misaligned. CCPs and market participants shall work together to assure the financial system's resilience (Friesz, 2020). Gregory (2014) states that CCPs convert counterparty risk into liquidity, operational and legal risk.

A further disadvantage is that clearing through CCPs on the OTC markets is the assets' maturity, liquidity, and complexity. If the positions opened for a short period, usually weeks to months, a CCP proves to be more effective as the OTC market's assets. These have a considerable maturity that can even last for decades, so handling counterparty risk on futures and spot markets working with a shorter timeframe is more efficient than on the OTC market. (Gregory, 2014). For instance, a ten-year credit default swap is not uncommon in these markets (Murphy, 2013). Moreover, the exchange-traded assets are standardized, not too complicated, and liquid. So handling counterparty risk on OTC markets, where the assets are complex, traded volumes are not concentrated in highly liquid assets, is inefficient and too expensive to clear through a CCP. For example, a stressed market condition to close down a position can take some days because of illiquidity. It can also happen that for non-standardized and exotic OTC derivatives, central clearing is just not feasible. However, the most crucial reason against CCP central clearing is that the OTC markets are the central place of financial innovations and offer cost-effective and well-tailored risk 
reduction products. Nevertheless, these new, non-standardized, or exotic products cannot be cleared by CCPs (Gregory, 2014).

\section{Clearinghouses vs central counterparties}

The primary role of clearinghouses and central counterparties is the clearing and the settlement of trades. The first significant difference is that a clearinghouse is operating on exchange markets, while CCPs can operate on exchange markets and OTC markets. Regarding the risk-overtaking mechanism, the CCP takes over the counterparty risk during trading, so there is a novation process by becoming the seller to every buyer and every seller, while a clearinghouse usually does not do this. So in the case of OTC CCPs, the two trading parties are no longer exposed to each other but only to the CCP, providing insurance against bilateral default risk (Biais et al., 2016). The netting of the transactions is different since a CCP always nets transactions, while clearinghouses do not necessarily. Another striking dissimilarity relates to the fact that in OTC CCPs, the trades are not necessarily cleared daily (Berlinger et al., 2016). Overall, every CCP has the activity of a clearinghouse, while not every clearinghouse can be regarded as a CCP (DNB, 2013).

It is critical to note that several margin notions are related to trading needing to be used appropriately: initial margin (IM), maintenance margin (MM), variation margin (VM), and margin call. The notions' meaning may, depending on which margin is being referred to, securities margin, futures margin, or the CCP margin. Securities margin is not in the scope of this paper, although it is also related to trading with the financial assets but has nothing to do with the clearing activity. This type of margin is a partial downpayment
- usually up to 50\%, regulated by Regulation $T$ (Reg T, 2021) - of the financial asset's price for the broker. The trader has to pay this amount to his broker and borrow the remaining amount from his broker to buy the financial assets, usually known as 'buying on margin' (CFA, 2017).

Throughout this paper, futures margin is the margin calculated by clearinghouses only in exchange trading, while the CCP margin is calculated by the CCPs and can be used in the markets it clears (both exchange- and OTC trading). In both cases, the trader becomes a member of the system, and it will be a clearing member having an obligation to pay the variation margin and the initial margin imposed by the entity.

The initial margin aims to limit the impact of a traders' position and cover potential future costs a CCP or a clearinghouse may face in normal market conditions if it defaults. The value of the IM is usually based on a risk measure. For example, the EMIR framework formulates a set of rules a CCP must comply with, depending on which market the asset is cleared: on the OTC market should be enough to cover losses on a $99.5 \%$ significance level, with a 5-day liquidation period, while for the exchange-traded asset, 99\% significance level, and 2-day liquidation period should be applied. The model shall contain a stressed time period, and the lookback period for estimating the parameters should 12 months. (EMIR, 2012, RTS, 2013). While the DFA is not as detailed as the EMIR regarding the IM model's parameters, and it just quantifies the application of the $99 \%$ significance level (SEC, 2021a), it still requires a conservative sizing of the initial margin requirements. Moreover, another notable difference between the two regulations from the IM perspective is that EMIR emphasizes considering procyclicality - the IM should not be procyclical -, while DFA does not. 
The first payment and the trading process of how the IM is requested in the futures margining and the CCP margining are different. Regarding the futures margining, the clearing member cannot enter into trading without paying the IM first (CME Group, 2021a). Meanwhile, a CCP requires the initial margin payment after the first trading day is over, when the transactions are cleared (Hull, 2018).

During bilateral trading, the payment of initial margin is not applied in most of the trades. BCBS-IOSCO (2015) states that the total initial margin on bilateral transactions not cleared by a CCP represents only $0.03 \%$ of the gross notional exposure in 2012. In 2011 a Working Group on Margin Requirements was formed to work out a margining framework on the bilateral trades. Based on this work, financial firms and systematically important non-financial institutions should use initial margins above a certain threshold, applying a 99\% significance level and a 10-day liquidation period (BCBS-IOSCO, 2015).

Before the current regulatory framework has been worked out, variation margin was already required for OTC derivatives contracts. However, the calculation and exchange were not regulated, therefore it was often irregular or incomplete. The variation margin usually has to be paid daily if the open positions are mark-to-market, so the trader loses or gains on a specific trading day, depending on price movements and positions. In the case of the CCP margin, if the trader gains on the open position on a particular day, the trader has access to this amount and can withdraw the gained amount from the collateral account. If there is a loss on the position, an obligation is generated towards the CCP to pay this loss as a variation margin. As a result, the losses will increase the amount of collateral to be paid, while the gains decrease it.

The futures margin has a different way of operation when the clearing of the actual loss/profit generates. If the trader has a loss/ profit when his position is marked-to-market, this loss/profit is subtracted/added to his actual margin account balance. If the loss is so extensive that this balance falls to the level - or below - a pre-set limit, the so-called maintenance margin, the trader will get a margin call. The margin call is the obligation of the trader to increase its margin account balance to the initial margin level, and this amount will be the variation margin. Overall, the variation margin needs to be paid to reach the margin account balance's initial margin value (CME Group, 2021a). Maintenance margin is not applied in the case of the CCP margin since, in most cases, there is a daily basis of marking-to-market and requiring the inclusion of collateral.

The notions described are the basics of futures margining and CCP margining on the individual financial assets' level. Every CCP or clearinghouse can apply different calculation methodologies. For example, they are free to set the parameters of the IM model or the risk measure they use. Also, the application of the calculated IM value to define the final collateral value may differ. An example of this is the CME Group's Standard Portfolio Analysis of Risk (SPAN) methodology, which defines the margin on a portfolio level (CME Group, 2021b). Several CCPs, outside the US, use this approach besides CME Group, e.g., LCH Clearnet (LCH. Clearnet, 2021), KELER CCP Ltd, the CCP of Hungary (KELER CCP, 2021)., KDPW CCP, the Polish CCP (KDPW 2021).

\section{Clearing in the USA and the EU}

There are 19 CCPs in the EU from 15 different countries (EACH, 2021) with the EMIR recognition for providing clearing and settlement services on exchanges and OTC markets in the European Union. The supervisor 
for all of them is their national supervisor, e.g., the national bank and the European Securities Market Authority (ESMA) on the EU level. It is important to note that not only an EU-based country can get EMIR recognition (ESMA, 2021). If a CCP proves that its operation and risk management process is prudent enough, it can achieve an EMIR license. Moreover, the European Commission and the CFTC agreed on a common approach to cross-border processes. The announcement made on $10^{\text {th }}$ February 2016 permits derivatives clearing organizations (DCOs) and CCPs to clear derivatives for counterparties abroad. (Doyle, 2016). Today, in the USA, six CCPs clear the most important US financial markets, five of which are designated as systemically important financial institutions, supervised by the SEC. Besides the six institutions, nonUS clearinghouses, the ICE Clear Europe Limited and the LCH SA (SEC, 2021b) also belong under the SEC's supervision. The US regulatory framework, too, mutually accepts non-US CCPs with the condition to have as prudent and robust applied operation as the local one.

In sum, no matter which markets a trader chooses, CCPs or clearinghouses are designed to ensure that they will break contagion among their members and mitigate systemic risk across markets and economies.

\section{MODEL}

Although jurisdictions differ and CCPs have the freedom to choose the best method to set up their daily operations, the primary purpose is prudence and consistency. This paper aims to show how different margin calculation methodologies can alter the results that quantify the same risk. The simulation shows how the margin calculation in the futuresand CCP margining work for a futures stock position. The following assumptions were implemented in the simulation.

The logreturn of the stock follows arithmetic Brownian motion (ABM) based on Equation 1.

$$
d Y=\alpha \cdot d t+\sigma^{*} \sqrt{d t} \cdot N(0,1)
$$

where ' $d Y$ ' is the change in the logreturn during ' $d t$ ' period, $\alpha$ is the expected value of the logreturn, $\sigma$ is the standard deviation for the logreturn, and ' $N(0,1)$ ' is a standard normal random variable. The expected value of the logreturn $(7.71 \%)$ and the standard deviation $(22.37 \%)$ were estimated from the DAX index's time series data in the period of $12^{\text {th }}$ January 1991 and $11^{\text {th }}$ January 2021.

The simulated logreturn time series contained stressed periods as well. The occurrence of the stress is modeled with a Poisson process with a lambda parameter of 0.005 , while the extent of the shock is modeled with a lognormal distribution with a mean of -10 and a standard deviation of 2.25. The decay of the shock is modeled with a 0.97 parameter. Finally, the stock price is determined by Equation 2, where ' $t$ ' stands for time, and ' $S$ ' stands for the asset's price.

$$
S_{t}=S_{0} \cdot e^{Y_{t}}
$$

The prices are simulated for 500 days, from which the first 250 is used to define the initial margins input parameters, and the remaining 250 days will be used to calculate the IM, VM, MM on a daily basis.

The initial margin is defined with the model proposed by Béli-Váradi (2017), which is based on the Value-at-Risk model and applies a $25 \%$ procyclicality buffer, which is exhausted if the exponentially weighted moving average (EWMA) standard deviation of the stock's logreturn is more significant than its equally weighted standard deviation. This IM value 
will be the same for both (futures and CCP) margining methods.

The IM calculation follows the parameters such as the lookback period is 250 days; the significance level is $99 \%$; the liquidation period is two days; the lambda parameter of the EWMA standard deviation is $1 \%$.

The maintenance margin will be $75 \%$ of the actual day's initial margin value.

Assumptions regarding handling the gains and losses of the marked-to-market valuation will be different, based on how it works in practice. In both cases, the assumption is that the marked-to-market valuation happens on a daily basis after the closing price is available on the market.

$>$ CCP margining: the variation margin requirement will be paid to the CCP if the trader had a loss on that day, while he will receive money back if he had a gain, so it will always have a cash flow effect. The margin account balance will always be the level of the initial margin. So if the initial margin's value is changing, the clearing member will have to increase/decrease the margin account balance.

$>$ Futures margining: if the trader makes a loss, it will be subtracted from the margin account balance till the maintenance margin is lower than this balance, so it will not have an actual cash flow effect. If its MM is higher, the trader will get a margin call and will have an obligation to increase the margin account balance to the IM level. If the trader makes a gain, it will increase the margin account balance, but only till the level of the initial margin requirement. If the balance has reached the initial margin value, the surpluses can be taken away by the clearing member.

\section{RESULTS}

The simulations were carried out 1000 times. Table 1 and Table 2 shows one of the realizations' results. A 10-day sample of a simulated margin calculation series can be seen in the tables, which show the IM, MM, VM, margin call, and cash flow dynamics. The main goal with the simulation was to show how the margin account and how the cash flows paid/ received by the clearing member change over time if the clearing member has a long open position in the stock futures positions. The risk-free return is assumed to be $0 \%$, so the futures price will be equal to the spot price of the underlying stock.

By analyzing and comparing the cash flows first (last column of Table 1 and Table 2), it can be stated that the futures margining has an advantage over the CCP margining. This benefit comes from the fact that it does not necessarily have a cash-flow effect every day, which is good from a daily liquidity management perspective. It is also shown in Figure 2, where one realization can be seen for 250 trading days. The Figures show the same pattern as Tables 1 and 2. It is essential to see that there was less cash-flow in the futures margining since the losses did not have a cashflow effect unless the trader has received a margin call (green line) or realized gain above the initial margin. In contrast, in the CCP margining case, there was a cash-flow every day because of the daily variation margin or because the initial margin changes.

Regarding the margin account, the difference is notable since, in the case of the CCP margining, it is relatively stable compared to the futures margining case, where this account is changing from day to day because of the marked-to-market valuation. Moreover, in the case of the futures margining, the value of the margin account is always lower or equal to the margin account of the CCP margining, so it provides less security. In sum, the futures margining is better from a liquidity management point of view, but the 'price' of this is less secure. 


\section{SIMULATED MARGIN ACCOUNT AND CASH FLOWS IN CASE OF THE FUTURES MARGINING}

\begin{tabular}{|c|c|c|c|c|c|c|c|c|}
\hline \multicolumn{9}{|c|}{ Futures margin } \\
\hline Day & Stock price & $\begin{array}{l}\text { Initial } \\
\text { margin }\end{array}$ & Daily gain & $\begin{array}{c}\text { Gumulative } \\
\text { gain }\end{array}$ & $\begin{array}{l}\text { Margin } \\
\text { account }\end{array}$ & $\begin{array}{c}\text { Mainte- } \\
\text { nance } \\
\text { margin }\end{array}$ & $\begin{array}{c}\text { Margin } \\
\text { call }\end{array}$ & $\begin{array}{l}\text { Cash } \\
\text { flows }\end{array}$ \\
\hline 251 & 1241 & 70.00 & 15.00 & 15.00 & 70.00 & 52.50 & 0.00 & -70.00 \\
\hline 252 & 1224 & 70.00 & -17.10 & -2.10 & 52.90 & 52.50 & 0.00 & 0.00 \\
\hline 253 & 1213 & 70.00 & -11.02 & -13.11 & 41.89 & 52.50 & 28.11 & 0.00 \\
\hline 254 & 1211 & 70.00 & -1.21 & -14.33 & 68.79 & 52.50 & 0.00 & -28.11 \\
\hline 255 & 1229 & 70.00 & 17.56 & 3.23 & 70.00 & 52.50 & 0.00 & 16.34 \\
\hline 256 & 1234 & 70.00 & 5.37 & 8.60 & 70.00 & 52.50 & 0.00 & 5.37 \\
\hline 257 & 1219 & 70.00 & -14.96 & -6.36 & 70.00 & 52.50 & 0.00 & 0.00 \\
\hline 258 & 1174 & 70.00 & -45.11 & -51.48 & 31.64 & 52.50 & 38.36 & 0.00 \\
\hline 259 & 1171 & 70.00 & -3.36 & -54.84 & 66.64 & 52.50 & 0.00 & -38.36 \\
\hline 260 & 1183 & 70.00 & 11.59 & -43.25 & 70.00 & 52.50 & 0.00 & 8.23 \\
\hline
\end{tabular}

Note: the underlying asset's initial value is 1000 units

Source: Own editing

Table 2

\section{SIMULATED MARGIN ACCOUNT AND CASH FLOWS IN CASE OF THE CCP MARGINING}

\begin{tabular}{|c|c|c|c|c|c|}
\hline \multicolumn{7}{|c}{ COP margin } \\
\hline Day & Stock price & Initial margin & Variation margin & Margin account & Cash flows \\
\hline 251 & 1241 & 70.00 & 15.00 & & -55.00 \\
\hline 252 & 1224 & 70.00 & -17.10 & 70.00 & -17.10 \\
\hline 253 & 1213 & 70.00 & -11.02 & 70.00 & -11.02 \\
\hline 254 & 1211 & 70.00 & -1.21 & 70.00 & -1.21 \\
\hline 255 & 1229 & 70.00 & 17.56 & 70.00 & 17.56 \\
\hline 256 & 1234 & 70.00 & 5.37 & 70.00 & 5.37 \\
\hline 257 & 1219 & 70.00 & -14.96 & 70.00 & -14.96 \\
\hline 259 & 1174 & 70.00 & -45.11 & 70.00 & -45.11 \\
\hline
\end{tabular}

Source: Own editing 


\section{CASH-FLOWS FROM THE CLEARING MEMBER'S POINT OF VIEW}

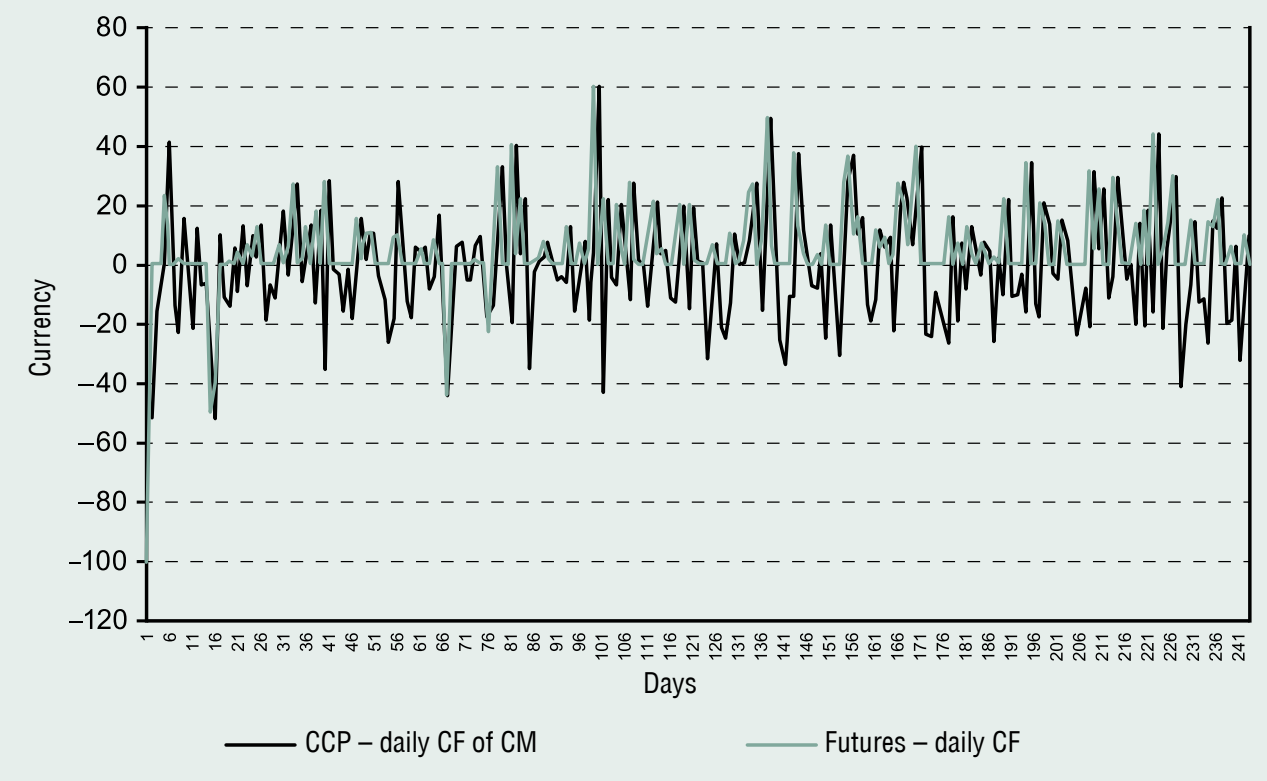

Source: Own editing

Figure 3 shows the time series of the margin accounts for 250 days.

The difference between the CCP and futures margining is important from a procyclicality point of view since when prices are falling, it usually happens when a shock hits the market. If the margin requirements increase when there is a shock and prices are falling, it is not as efficient from the traders' point of view and can easily cause liquidity problems to finance the increasing collateral requirements. Interestingly, in the case of the CCP margin, the notable point is to handle procyclicality throughout defining the IM in the EMIR framework; meanwhile, futures margining does not focus on this phenomenon. At the same time, the futures margin account decreases with the falling prices, while the CCP margin account does not decrease. Moreover, on those days when the prices all falling, the trader on the CCP cleared market has to pay the losses as variation margin, so it has to provide extra liquidity, while in the case of the futures margining it does not have to do so unless it reaches the level of the maintenance margin.

Besides liquidity and procyclicality issues from which viewpoint the futures margining proves to be better -, there are other essential characteristics of the margin balance, which are more critical than liquidity and procyclicality, namely how good and prudent the model is. This can be quantified by the backtest, which compares a certain day's price change to the margin account balance: whether the margin was enough to cover the price change.

Figure 4 shows the result of the relative frequency of the backtest results. Results show that the CCP margin in $22.5 \%$ of the cases was enough to cover losses every day 
Figure 3

\section{MARGIN ACCOUNT BALANCES}

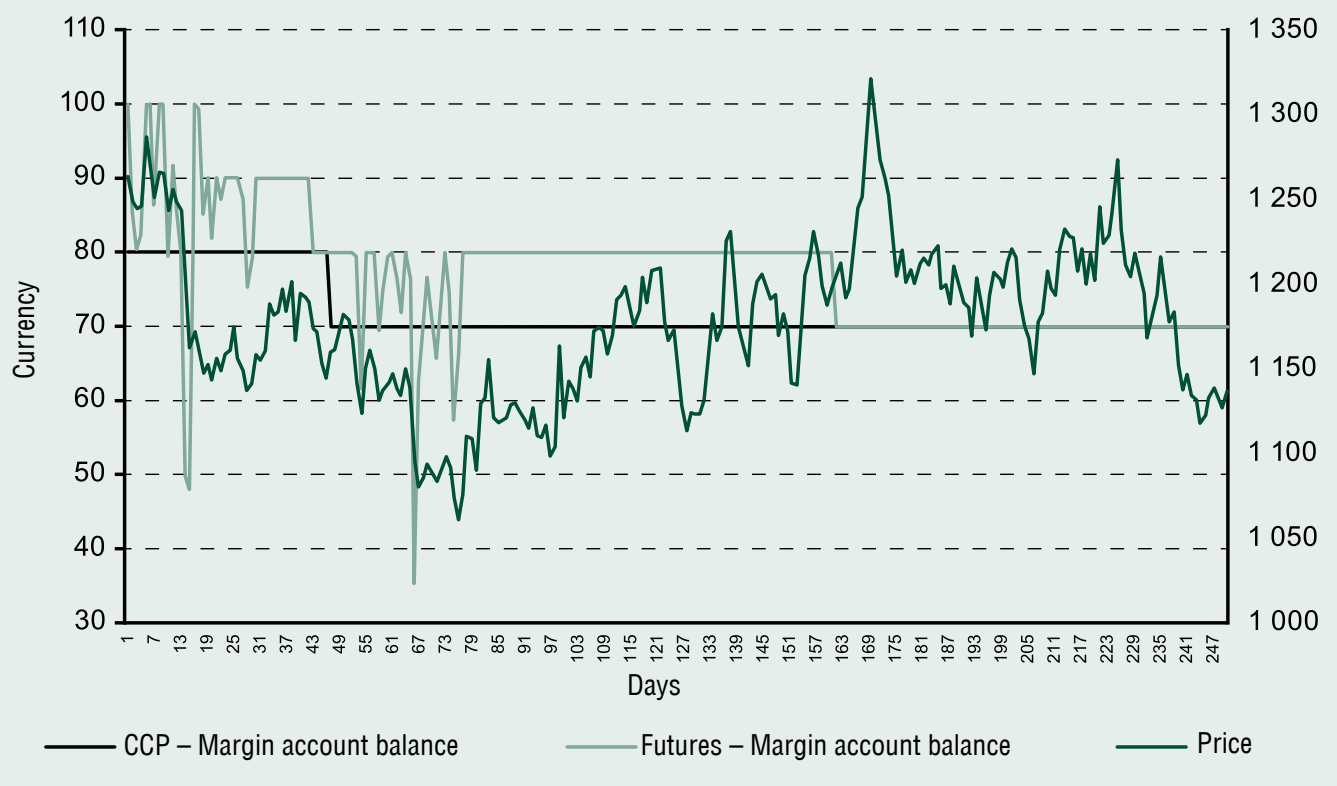

Source: Own editing

Figure 4

\section{BACKTEST RESULTS}

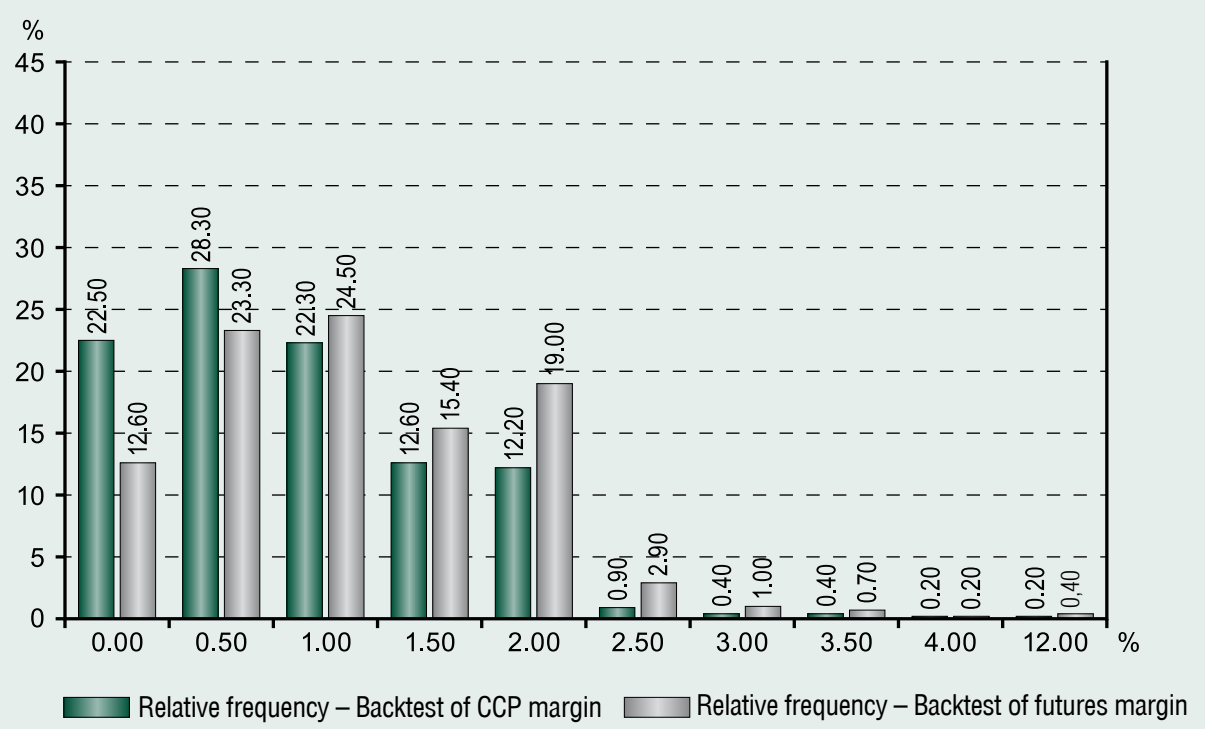

Source: Own editing 
throughout the 250 days, for which the margin was simulated, while in the futures margining case, this is only $12.6 \%$. Since the VaR model was calibrated on the $99 \%$ significance level, it was expected to have most of the results around $1 \%$. The cumulative frequency till the $1 \%$ backtest result is around $70 \%$ of the CCP margining case ${ }^{1}$ and only around $60 \%$ of the futures margining case. So it can be stated that the CCP margining is better from a backtesting point of view. Although in $1.3 \%$ of the simulated cases, the futures margin was better from a backtesting perspective. In contrast, the CCP margining was superior in $39.5 \%$ of the cases, and in the rest of the simulations, the two methods backtest had the same results, according to Table 3 .

Although CCP margin performed much better than the futures margin from a backtesting point of view, it is also important that which margining method is stricter from the overmargining point of view. If the margin is always unreasonably too high, it is easy to have a good backtest result, which is good from a risk management point of view, but not necessarily good from the clearing members' since it takes away too much liquidity from them. Also, the CCP may have a competitive disadvantage if it is too expensive, requires too much collateral. The overmargining is defined as the ratio of the margin account a certain day and the actual price change, so how many times did the margin cover the possible losses. The ratio was quantified for all 250 days, and the average of these values in every simulation was used. Figure 5 contains the relative frequency of these average overmargining values. On the $\mathrm{x}$-axis, is shown how many times the margin value exceeded the price changes, while the $y$-axis contains the relative frequency of these possible outcomes. On the 20-time, the futures margin was more frequent, while on a higher level, the CCP margining is usually more frequent. This result means that in the futures margining case, the overmargining was on a lower level. Table 4 presents how many times the CCP margin was best and how many times the futures margining excelled. Better in this sense means that the overmargining was lower. So from this point of view, the futures margining was better.

Overall, the CCP margining performed better from a compliance aspect since the backtesting results gave more satisfying results. However, from the clearing members' perspective, this leads to higher margin requirements, so overmargining and, therefore, extracting liquidity from the market is a disadvantage. The futures margin model performed better from a procyclicality, burdening the members less but putting more risk on the CCP.

\section{CONCLUSION}

Our results show that calculating the margin balance with the futures margining or the

Table 3

\section{COMPARISION OF THE BACKTEST RESULTS}

\begin{tabular}{c|c|c}
\hline \multicolumn{2}{c}{ Backtest result } \\
\hline BCP is better & Futures is better & Same \\
\hline 39.50 & 1.30 & 59.20 \\
\hline
\end{tabular}

Source: Own editing 


\section{OVERMARGINING}

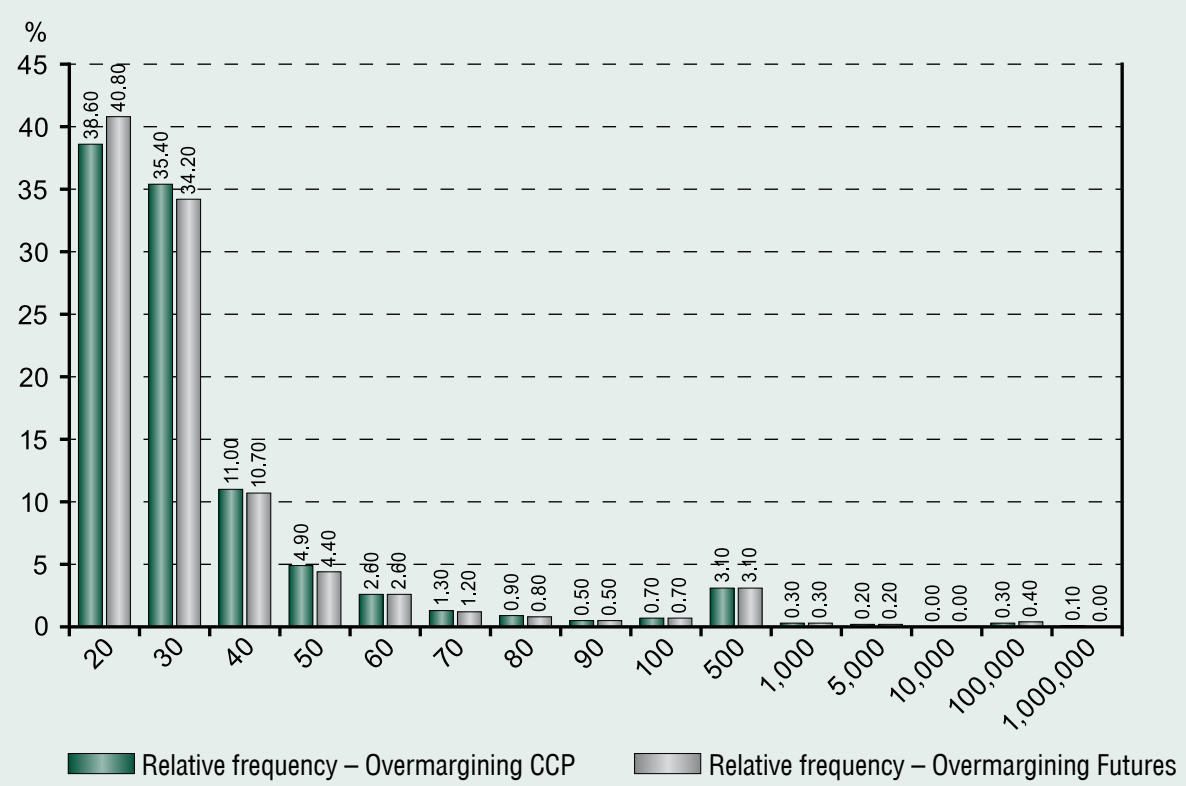

Source: Own editing

Table 4

\section{COMPARISION OF THE OVERMARGINING}

\begin{tabular}{c|c|c|}
\hline \multicolumn{2}{c}{ Overmargining } \\
\hline BCP is better & Futures is better & Same \\
\hline 11.10 & 88.80 & 0.10 \\
\hline
\end{tabular}

Source: Own editing

CCP margining can lead to a much different margin account balance, although the initial margin requirements were calculated the same way. The simulation was run 1000 times. The main result was that from an everyday liquidity management point of view regarding cash flow movements and overmargining, the futures margining is better from the clearing members' perspective. Moreover, also from a procyclicality aspect, the futures margining proved to be better. Nevertheless, the overall results show that the CCP margin was better from the model adequacy perspective. Namely, it performed much better on the backtest, so from a prudency perspective, it is superior.

Future proposed research regarding this topic is to examine this question with procyclicality measures. 


\section{Note}

1 The reason why these values are not around $99 \%$, is coming from the margin calculation methodology of Béli-Váradi (2017), where there would be additional buffers applied in order to have an adequate back test result, whic buffer are set to $0 \%$ in this calculation. These buffers are the liquidity and expert buffer.

\section{ReFERENCES}

Amini, H., Cont, R., Minca, A. (2016). Resilience to Contagion in Financial Networks. Mathematical Finance, 26(2) pp. 329-365

BÉLI, M, VÁrAdI, K. (2017). Alapletét meghatározásának lehetséges módszertana. Financial and Economic Review, 16(2) pp. 117-145

Béres, D. (2018). Securities Post-trading Infrastructure - Past, Present and Future. Public Finance Quarterly, 63(4), pp. 564-580

Berndsen, R. (2020). Five Fundamental Questions on Central Counterparties (SSRN Scholarly Paper ID 3709691). Social Science Research Network.

https://doi.org/10.2139/ssrn.3709691

Berlinger E., Dömötör B., Illés F., VÁRAdI K. (2016). A tőzsdei elszámolóházak vesztesége. Közgazdasági Szemle, 63(9) pp. 993-1010

Biais, B., Heider, F., Horeova, M. (2016). Risk-Sharing or Risk-Taking? Counterparty Risk, Incentives, and Margins. Journal of Finance, 71(4), pp. 1669-1698

Doyle, J. Lewis, S., Dillon D., Merlini, K. Hudd, D., Koster, E.M., May, B., Wright, I. (2016). Summary of key EU and US regulatory developments relating to derivatives. Hogan Lovells report, June 2016
Duffie, D., Zhu, H. (2011). Does a central clearing counterparty reduce counterparty risk? Review of Asset Pricing Studies, 1(1) pp. 74-95

Friesz, M. (2020). The Financial System's Resilience is Everything, But at What Cost? Public Finance Quarterly, 65(4), pp. 472-484. https://doi. org/10.35551/PFQ_2020_4_2

Gregory, J. (2014). Central Counterparties, Mandatory Clearing and Bilateral Margin Requirements for OTC Derivatives. John Wiley \& Sons Ltd. United Kingdom

Huang, W., Takáts, E. (2020). Model risk at central counterparties: Is skin-in the-game a game changer? BIS Working Papers, 866, https://ssrn.com/ abstract $=3613194$

Hull, J. C. (2018). Options, Futures, and Other Derivatives, 10th Edition. Pearson.

King, T., Nesmith, T. D., Paulson, A., Prono, T. (2020). Central Clearing and Systemic Liquidity Risk. Finance and Economics Discussion Series, 2020(9)

Lopez, C., Saeidinezhad, E. (2017). Central Counterparties Help, But Do Not Assure Financial Stability. Munich Personal RePEc Archive

McPartland, J. W., Lewis, R. (2014). The Goldilocks Problem: How to Get Incentives 
and Default Waterfalls "Just Right." Economic Perspectives, 41(1)

Murphy, D. (2013). OTC Derivatives: Bilateral Trading \& Central Clearing, An Introduction to Regulatory Policy, Market Impact and Systemic Risk. Global Financial Markets series. PalgraveMacmillan. NY

Norman, P. (2011). The Risk Controllers - Central Counterparty Clearing in Globalised Financial Markets. John Wiley \& Sons Ltd. United Kingdom

Turing, D. (2012). Clearing and Settlement in Europe. Bloomsbury Professional, Haywards Heath

BCBS-IOSCO (2015). Margin requirements on non-centrally cleared derivative. Bank for International Settlements, March 2015, https:// www.bis.org/bcbs/publ/d317.pdf

BIS (2012). Bank for International Settlements: Payment, clearing and settlement systems in the United States - CPSS Red book. https://www.bis. org/cpmi/publ/d105_us.pdf

CFA (2017). Equity and Fixed Income - CFA Program Curriculum, Level I, Volume 5. CFA Institut

CFI (2021). Corporate Finance Institute: National Securities Clearing Corporations. https://corporatefinanceinstitute.com/resources/ knowledge/trading-investing/national-securitiesclearing-corporation-nsccl

CME Group (2021a). Margin: Know What's Needed. https://www.cmegroup.com/education/ courses/introduction-to-futures/margin-knowwhat-is-needed.html

CME Group (2021b). SPAN Methodology. https://www.cmegroup.com/clearing/risk-manage ment/span-overview.html
DNB (2013). De Nederlandsche Bank - All the Ins and Outs of CCPs. https://www.dnb.nl/en/ binaries/711869_All_Ins_Outs_CCPs_EN_web_ v3_tcm47-288116.pdf

DFA (2010). Dodd-Frank Wall Street Reform and Consumer Protection Act. 2010, Public Law 111203. Available: https://www.cftc.gov/sites/default/ files/idc/groups/public/@swaps/documents/file/ hr4173_enrolledbill.pdf

DTCC (2021). Depository Trust \& Clearing Corporation homepage - CCP Resiliency and Resources. https://www.dtcc.com/news/2015/february/02/ccpresiliency-and-resources

EACH (2021). European Association of CCP Clearing Houses. https://www.eachccp.eu/ members/

EMIR (2012). European Market Infrastructure Regulation: Regulation (EU) No 648/2012 of the European Parliament and of the council of 4th July 2012 on the OTC derivatives, central counterparties and trade repositories. https://eurlex.europa.eu/legal-content/EN/TXT/?uri=celex \%3A32012R0648

ESMA (2021). European Securities Market Authority - list of non-EU CCPs with EMIR recognition. https://www.esma.europa.eu/sites/ default/files/library/list_of_applicants_tc-ccps. pdf

Eurex (2021). Eurex AG homepage. https://www. eurex.com/ec-en/

ICE Clear Credit (2021). Homepage of ICE Clear Credit https://www.theice.com/clear-credit

ICE (2021). Intercontinental Exchange homepage - Manage your risk - How clearing works? https:// www.theice.com/publicdocs/How_Clearing Works.pdf 
KDPW CCP (2021) Homepage of KDPW CCP http://www.kdpwccp.pl/en/Risk-Management/ Documents/SPAN_Methodology_derivatives_ market.pdf

KELER CCP (2021). Homepage of KELER CCP Ltd. https://english.kelerkszf.hu/Risk\%20Management/Initial\%20margin\%20calculator/

LCH. Clearnet homepage (2021) https://www. lch.com/services/equityclear/equityclear-sa/riskmanagement/sa-span-derivatives-clearing-systemspublic-1

OCC (2021). Options Clearing Corporations homepage - What is OCC? https://www.theocc. com/Company-Information/What-Is-OCC

PFMI (2012). Principles for Financial Market Infrastructures. CPSS-IOSCO, Bank for Inter_ national Settlements, April 2012. https://www.bis. org/cpmi/publ/d101a.pdf
Reg T (2021): Regulation T, https://www.ecfr.gov/ cgi-bin/text-idx?tpl=/ecfrbrowse/Title12/12cfr220_ main_02.tpl

RTS (2013). Technical Standard: Commission delegated regulation (EU) 153/2013 of 19th December 2012 supplementing Regulation (EU) No 648/2012 of the European Parliament and of the Council with regard to regulatory technical standards on requirements for central counterparties. https://eur-lex.europa.eu/legal-content/EN/TXT/? uri=CELEX\%3A32013R0153

SEC (2021a) Capital, Margin, and Segregation Requirements for Security-Based Swap Dealers and Major Security-Based Swap Participants and Capital and Segregation Requirements for Broker-Dealers https:/www.sec.gov/rules/final/2019/34-86175.pdf

SEC (2021b). Securities and Exchange Commission Homepage. https://www.sec.gov/tm/ clearing-agencies 